\title{
Assessment of International Students' Satisfaction with Regard to the Information Systems at the Overseas Educational College (OEC) of Jiangsu University, China
}

\author{
Samar Zaineldeen Li Hongbo Masud Ibrahim Koffi Aka Lucien \\ School of Management, Jiangsu University, Xuefu Rd ,JingKou,Zhenjiang, Jiangsu , China
}

\begin{abstract}
This study explored factors that influence user satisfaction of information portal of higher education institutions. Data for the study was obtained from some selected undergraduate and postgraduate overseas students of Jiangu University, China. A sample of 500 students was selected using proportional stratified sampling technique. A self structured questionnaire was used to collect data from the study respondents. The data was analysed using the PLS-SEM technique and a detailed analysis of basic factors impacting the user satisfaction. The result shows that all the information system characteristics (system quality, information quality and service quality) positively influence user satisfaction. The system quality had the highest influence among the factors affecting user satisfaction $(\beta=0.391)$. This study further revealed that sustaining information quality eventually leads to user satisfaction with information quality $(\beta=0.352)$ and influence students' satisfaction of the web portal. However, among the the three user satisfaction influencing factors, the service quality factor was observed to cast a minimal direct impact on the user satisfaction service quality $(\beta=0.200)$. This study contributes to the literature on higher education institution management.
\end{abstract}

Keywords: Student Satisfaction, Information Quality, Service Quality and System Quality.

DOI: $10.7176 / \mathrm{IKM} / 9-10-05$

Publication date: November $30^{\text {th }} 2019$

\section{Introduction}

The substantial development in the education sector in China has given a significant rise to competition among organizations within the sector. Located in China, Jiangsu University is one of the leading universities in China with respect to the number of international students and study programs. The Student Facilitation or Information system assists the management of student-related information throughout the fundamental business activities i.e. admission, accommodation, examination, registration, grade distribution, the offering of courses, class timetables and records. The major motive of this study is the assessment of international student satisfaction with regard to the information systems in international college i.e. overseas educational college (OEC) (Gao \& Wit 2017).

Due to the advancement of communication and information technologies as well as the internet, a dramatic change has been noticed in the computing experience and environment of the end user. Furthermore, this progress has affected the process of delivering information and services. Unlike the conventional halted information systems, the advanced information systems are now web-enabled. Web portals being one of the biggest parts of the advanced information systems.

A Web portal is an access to data and facilities from several sources in an integrated method, by a particular, exclusive user interface (A. Tatnall 2005). A Web portal generally fulfills a particular set of functions involving database access, mechanisms for search, user registration and individualized options. Web portals fulfill several causes, such as private, administrative, informational, entertaining and educational commitments (A. Tatnall 2009). Regardless of the rapid increase in web-based information systems and the dramatic changes in the computing environment of end-user over the past decade, there still has been the inappreciable amount of research done on quantification of user satisfaction throughout the web-built information systems, particularly in the academic domain. The usage of web portals has enabled the universities to set a foothold for enlargement, the introduction of up-to-date utilities and the development of qualitative and quantitative processes of conveying data and functionalities in overseas education. Moreover, the increase in user informational requirements in the education sector has caused extensive investment in web portals for Overseas Education College. Therefore, there is a required need for stakeholders to rationalize this huge investment in this sector by determining the influence of the information system on the satisfaction of end-users. The user's satisfaction is considered as the entity's usability criteria towards the computer, or behavior for other activities necessary to perform in an organization (Rainer \& Harrison 1993).

For the sake of descriptive survey of the Jiangsu University for the overseas students' satisfaction, 500 representatives as a sample of international students were chosen through a proportional stratified sampling method. Data collection was carried out through a self-structured questionnaire and analyzed through descriptive and inferential statistics. Use need to be placed behind client satisfaction during the process sense, yet constructive participation with utilization will cause more projecting user contentment in a casual way. Greater user 
contentment perpetually prompts a higher goal to utilize. Client satisfaction is estimated by the clients' dimension of satisfaction with reports, websites, and support services. To measure information system's performance, client satisfaction is perhaps the most broadly utilized single measure (Igbaria \& Nachman 1990), (DeLone \& McLean 1992),( Igbaria \& Tan 1997). The web portal for Jiangsu university Liu et al. (2019) overseas education college was outlined to suffice the online services to both undergraduate and postgraduate students including effective admission processes, registration, payment of tuition fees, appeal for accommodation, verification of admission status and provision of fundamental details about the University. Regardless of the useful advantages of this system towards international students, its success will still be largely dependent on the students' satisfaction. The OEC web portal's performance can be measured successfully only through feedback from users. Through this feedback, acting as an indication and a weighbridge, users can validate their speculation and assess their strength in the progress of the system. The essential criticism can only be accomplished successfully through an analysis to discover the unguarded view of web portal's operators. The study will conclude to the forefront that which information system measurement indices are considered the most in users' contentment. The result will help users to manage assets suitably on the basis of the satisfaction directories observed initially.

\subsection{Need for Implementing An Information System}

Knowledge is the outcome of a continuum of how we progress raw data into valuable information (Whitten \& Bentley 2007). to convert data into beneficial information for awareness-based assessment making at any level, data must be gathered, structured, examined and reproduced upon (Tolley \& Shulruf 2009). Information is perpetually increased in all organization. The careful management and utilization of this information are on the growing concern to all organizations, and storing of functional information in an information system that can aid organizing and consolidating organization's information will produce considerably improved management choices. School can efficiently preserve records of students profile, grades, marks, timetable, absences, behavior statistics, medical record, and demographics (Creemers 2002).

The organization uses an information system for complete and consistent information that will be accessible when it is needed. As it is a difficult task to calculate the need for information, many organizations use technology i.e. computer to maintain corporate transactions. When a report must be created, this raw information can be recovered and deployed to produce the needed information Van et al. 2010.

Moreover, the growth in the number of students increases the complexity of handling the class schedules increases hence an information system helps to manage the timetables effectively at an education institute.

\subsection{Research Objective}

The following study focuses to comprehend the efficacy and satisfaction of the prevailing student information portal of overseas education college with regard to performance including system quality, user satisfaction, quality of service and information.

This research concludes the serviceability of the information system and the way students (undergraduate and postgraduate) discern its functionality in completing their requirements on the system.

\subsection{The Measure of Information System Success}

The key focus of the introducing of an information system into an organization is to enhance individual decisionmaking performance along with the efficacy and productivity of the overall organization. The success of the system plays an important role in the expected benefit in terms of organizational goals through the implementation and adoption of the information system. As mentioned earlier, the success of the information system is a multidimensional design (Saarinen 1996). For this reason, substitute methods have been developed and used to estimate the realization of the information system. The surrogate measures namely system usage (Nolan \& Seward 1974),( Nolan 1974),( Segev et al. 1984 ),( Snitkin \& King 1986) and user satisfaction (Bailey \& Pearson 1983),( Ives et al. 1983),( Baroudi \& Orlikowski 1988) are the two of them; described after examining 180 studies for information system success measures. Corresponding to them, the study has focused on the following areas: the quality of the system, quality of the information, user satisfaction, individual and organizational influence. Their model highlights the effects and inter-relationships among these numerous modules (Amoroso \& Cheney 1991). It has been also observed that information quality and system quality are two considerable components of user satisfaction. The model further proposes that user satisfaction, as well as system usage, are influenced by the two factors mentioned above Tan et al. 2004.

However, this study does not cover the effect of all the factors on the dependents rather it deals with the insight and explanation of the association among the following factors: the quality of the system, the quality of the service, and information quality and user satisfaction. This model classified the factors of the success into six credible dimensions along with the consolidation with the prior findings. Nevertheless, the suggested associations in their model were not put to a test factually. Various other studies (DeLone \& McLean 2002) empirically examined the association between the measures of the information system's success. In (Garrity \& Sanders 1998) 
determines the information system's realization at different stages - how a system subsidizes to the organizational presentation, proficient use of assets and the users' perception of utility and satisfaction.

\section{Methodology}

To scrutinize the information system users' contentment indices amongst the overseas students (undergraduate and postgraduate) of Jiangsu University in China a detailed survey design was applied. The sample of the students for this study comprises of overseas students from all departments in the university. This sample of 500 students was selected on the basis of proportional stratified sampling technique across the various faculties of the university. For the collection of the data, a self-structured questionnaire regarding information systems was designed. The survey was carried out directly (one to one) with the respondents. After the distribution and retrieving of the questionnaires, the data was acquired and found appropriate for the analysis of the data. Explanatory and inferential statistical methods were used for data analysis.

\subsection{Research Design}

The survey for the study was conducted using 5 point Likert's Scale Song et al. 2011 as the research design. It discusses the gathering of statistics from the users (overseas undergraduate and postgraduate students) of portal systematically. Their feedbacks are evaluated to provide a clear insight into the valuation of the user satisfaction level of the web portal information system.

\section{Related Literature}

The idea of user satisfaction can be drawn back to numerous years (Swanson 1974). With reference to (Bailey \& Pearson 1983) satisfaction is one's behavior towards a given situation and the factors affecting the situation". Along with the utilization of the system, various measures have been put forward for the evaluation and the calculation of user satisfaction (Baroudi \& Orlikowski 1988). In (kim 1989) explains user contentment with regards to the standard of information, the effectiveness of the system and attitude of the user. In (Doll \& Torkzadeh 1989) Considered user contentment with regards to the quality of the system and quality of information. In (Peter 1996) this research, 33 articles were attached highlighting the matter of user satisfaction. For the conclusion they proposed, the availability of the authentic tools to measure user satisfaction has made the user contentment as the widely used measure of information system success, while other measures are prone to failures.

There is a number of researches carried out on various approaches to estimating the functionality and efficacy of specific online service. The studies differ from the criteria adopted to evaluate the factors affecting the user satisfaction of a particular service provided online and the technology adoption model Qawasmeh et al. 2014 several models have been acquired by the researches to describe what factors make an information system 'successful.'

To describe the reason for the acceptability of an information system, "Theory of Reasoned Action and Theory of Planned Behavior" was used by the Technology Acceptance Model (TAM) (Fishbein 1977). However, acceptance is not identical to success; however, it is required pre-requisite for success. Delone and Mclean's information models are the one widely cited (Vardi \& Weitz 2002).

Caused by the complexity, multi-dimensional factor, and interdependency of information system success, the initial efforts to explain information system lacked the definition of success. To quantify the problem, a research's review was published (1981-1987) by DeLone and McLean (Petter \& McLean 2009), thus establishes a taxonomy of the realization of the information system on the foundation of this review. They pointed out six components of the information system's success in 1992, which are as follows: satisfaction of users, quality of the system, information quality, use, organizational and individual impact.

Nonetheless, these six modules are not self-supporting success measures but are dependent on each other. Many information system researchers started modifying the model after the D\&M model's publication. Seddon \& Kiew (Seddon \& Kiew 1996), after receiving the proposal for 'further development and validation' researched on a specific portion of the information system model. As part of their judgment, researchers revised the factor 'use' as they 'estimated that the fundamental successes constructs indicate that researchers have been attempting to tap are Usefulness, not Use. Although, the Seddon and Kiew's idea of usefulness is similar to the concept of identified usefulness in the Technology Acceptance Model (TAM) proposed by Davis (Davis 1989). They advanced that, 'use' is a suitable measure for the elective systems, but usefulness is superior to use the measure of information success if the use of the system is compulsory. In response to that, DeLone \& McLean (Delone \& McLean 2003) argued that the 'use' factor should be retained due to substantial variability of 'use'. It is also recommended by researches to include service quality to the D\&M model. An instrument known as SERVQUAL from the marketing literature has become noteworthy in the success of an information system from the past decade.

"SERVQUAL estimates the quality of service of IT departments, unlike the discrete IT applications, by quantifying and comparing expectations of the user and their understating of the IT department. Furthermore, Pitt et al. (1995) "assessed the instrument from the perspective of information system and proposed that the service 
quality component should be a part of the D\&M model. Some researchers have withstood this alteration (Seddon 1997), while the rest have supported it Jiang et al. (2002). After the careful review and evaluation, "DeLone and McLean decided to add a variable "service quality" in their updated information system model.

Another widely known amendment to the D\&M model is the one proposed by (Seddon 1997) He declared that the D\&M model on its own was obscuring due to the combination of process and variance models in the same framework (Desai \& Mahalakshmi 2018).

DeLone and McLean "argued on the amendment proposed by the Seddon, declaring that this was the strength of the model rather than a shortcoming because the two variables were richer together than alone. Moreover, Seddon recommended that the idea of 'use' is debatable and required a further explanation for this construct.

Seddon concluded three different possible definitions for the construct 'use' along with splitting the two portions process and differences within the model. The changes made by the Seddon complicated the model and thus affecting its impact while the D\&M model of the information system was supposed to be 'complete and parsimonious'. Notwithstanding the changes proposed by Seddon, there have been different calls to reexamine or broaden the model. A few analysts have altered it to assess the performance of explicit applications, for example, knowledge management (Jennex \& Olfman 2002),( Kulkarni et al. 2006) and internet business(Molla et al. 2001), (Zhu et al. 2005). Different specialists have made increasingly broad proposals concerning the model (Munro et al. 1996). Perceiving these proposed changes to their model, D\&M, in subsequent work, looked into experimental examinations that had been performed during the years since 1992 and overhauled the first model likewise. This refreshed IS performance model acknowledged the Pitt et al. (1995) proposal to incorporate service quality in the role of a constructor. Another additional update in the model tended to the analysis that a data framework can impact levels aside from individual and level. Since IS performance influences workgroups, ventures, and even social orders (Myers et al. 1997 ),( Nolan 1973),( Seddon et al.1999 ). D\&M supplanted the factors, singular impact, and authoritative effect, with net benefits, in this way representing advantages at various dimensions of examination. This correction enabled the model to be connected to whatever dimension of examination the specialist considers generally important. The last change added to the D\&M model was an explanation of use construct. The builders explained the construct as pursues: 'Utilize should be prioritized before "client satisfaction" in a method way, however, positive participation with "use" will lead to noteworthy "client satisfaction" in a causal way (Delone \& McLean 2003). They proceeded to convey that extended client satisfaction will influence a much higher aim to utilize, which will along these lines influence use. "The D\&M model has likewise been observed to be a valuable structure for getting sorted out IS performance estimations. The model has been broadly utilized by IS specialists for comprehension and estimating the elements of IS performance. Moreover, every one of the factors depicting the accomplishment of a data framework was reliable with at least one of the six noteworthy performance measurements of the refreshed model. The components of accomplishment include:

System Quality - the characteristics which are desired in an information system. For example, system flexibility, reliability, the learning curve, ease of use, and other system features of sophistication, flexibility, response times, and intuitiveness(Petter et al. 2008). Strong support has been acknowledged for the relationship between user satisfaction and system quality (Iivari 2005). Upon examination of more general ISs, a strong relationship was found between the quality of the system and user satisfaction (T. W. P. A 2005).

Information quality- the advantageous characteristics of the outputs of the system; including web pages and management reports. Such as accuracy, conciseness, completeness, understandability, relevance, usability and timeliness (Petter et al. 2008). The association between user satisfaction and information quality is highly encouraged in the literature (Wu \& Wang 2006). Service quality- A measure to determine the support quality provided to the system users by the IT employee staff and the information system department. Such as technical capability, responsiveness, reliability, and accuracy (Petter et al. 2008). a case study carried out by (Leclercq 2007 ) found that the association among the information system function and users along with the support quality and services influenced on user satisfaction.

\section{Result}

4.1 Confirmatory Factor Analysis (CFA)

Confirmatory Factor Analysis is used in the verification of the structural factor pertaining to the set of obtained values (Thompson \& Nier 2005 ). Since we are testing for the common method variance in our study, the Factor test was adopted and EFA was used for the test. This account for about $88.40 \%$ of the variance in the sample (See Table 1). 
Table 1: KMO and Bartlett's Test

\begin{tabular}{|c|c|c|}
\hline \multicolumn{2}{|c|}{ Kaiser-Meyer-Olkin Measure of Sampling Adequacy. } & .884 \\
\hline \multirow[t]{3}{*}{ Bartlett's Test of Sphericity } & Approx. Chi-Square & 1936.477 \\
\hline & Df & 15 \\
\hline & Sig. & .000 \\
\hline
\end{tabular}

\subsection{Reliability and Validity of Scales}

EFA was utilized through SPSS in measuring the underlying dimensions associated. Bartlett's Test of Sphericity was used in measuring the construct validity whiles the Kaiser-Meyer-Olkin (KMO) was used to measure the Sampling Adequacy of individual variables. Note that the overall of the KMO should be 0.6 or even more for the factor analysis (Özdamar 2017). According to the above results, it revealed that both are significant and it is suitable for the factor analysis (See Table 1). The cumulative variance in the table shows $88.40 \%$, which exceeds the minimum acceptance level of $60 \%$ (Özdamar 2017). The table again indicates that Bartlett's Test of Sphericity is sufficient for the correlation between the variables, it shows 1936 and significant $(\mathrm{P}>0.000)$. Whiles the factor loadings of the entire construct exceeded 0.5 (Hair et al. 1987). These values represent evidence that there is convergent and discriminate validity (See Table 4).

\subsection{Characteristics of Respondents Based on Demographics}

Table 2 contains the characteristics of the respondents based on the demography. Almost $52.4 \%$ of the respondents were male and almost $46.6 \%$ of the others were females. Age wise, those respondents who were aged 17-23 contributed with the highest percentage (51.2), following by the respondents of age 24-30 (32.8). Those between 31-37 and 38-44 years were (12.4) and (2.0) respectively, (1.6) for other ages. (58.2) of respondents were an undergraduate student while (41.8) were postgraduate students.

Table 2 the characteristics of the respondents based on the demography

\begin{tabular}{|l|l|l|l|}
\hline Variable & Measurement & Frequency & Percent \\
\hline \multirow{3}{*}{ Gender } & Male & 262 & 52.4 \\
\cline { 2 - 4 } & Female & 238 & 46.6 \\
\hline \multirow{5}{*}{ age } & $17-23$ & 256 & 51.2 \\
\cline { 2 - 4 } & $24-30$ & 164 & 32.8 \\
\cline { 2 - 4 } & $31-37$ & 62 & 12.4 \\
\cline { 2 - 4 } & $38-44$ & 10 & 2.0 \\
\cline { 2 - 4 } & Other & 8 & 1.6 \\
\hline Qualification & undergraduate & 291 & 58.2 \\
\cline { 2 - 4 } & Postgraduate & 209 & 41.8 \\
\hline
\end{tabular}

\section{Measurement Model Reliability and Validity}

\subsection{Data Analysis}

The simulation work in estimating the result of the perceived variables and their latent constructs on the contentment of user was implied in smart-PLS version 3.2.7 (Ringle \& Becker 2015) PLS-SEM is widely applied for theory development in analytic research (Bamgbade et al. 2017) The key applications of SEM are as follows: confirmatory factor analysis, regression models, path analysis, second-order factor analysis, correlation structure models and covariance structure models (Lin et al. 2017). In addition to that, SEM allows the examination of the linear associations between the manifest variables and the latent constructs. It also supports the creation of accessible parameter estimates for the association between undetected variables. Generally, SEM allows numerous relationships to be examined at once in a single model with different relationships rather than testing each relationship individually. Smart-PLS version 3.2.7 is more advantageous than a method based on regression for assessing various latent constructs with several manifest variables (Gefen 2000) PLS has a two-step process as suggested by Henseler et al. (2009) that includes the assessment of the inner structural model and outer measurement model. Furthermore, PLS-SEM is chosen as the most familiar technique within social sciences studies that is the most suitable procedure for multivariate analysis (Hair et al. 2014), (Peng \& Lai 2012).

\subsection{Evaluation of Outer Measurement Model}

The outer measurement model is directed to compute the internal consistency, reliability, and validity of the observed (assessed through the questionnaire) and unobserved variables (Ho 2006 ). Discriminant and convergent validity methods are applied to evaluate the validity while the consistency assessments are established on singled observed (Hair et al. 2012).

Construct reliability is the degree of consistency that is used to assess the extent to which various test items that review a similar construct establish comparable results. This is assessed through item loadings with an 
acceptable value of 0.70 and again using Cronbach's Alpha level of acceptable region of 0.70(Hair \& Sarstedt 2012). From the table below, the construct displays that the item loadings are all higher than the recommended 0.70 .

The reliability of a detected variable defines the variance of a single observed individual when compared to an unobserved variable. This is done by assessing the standardized outer loadings of all detected variables (Götz et al. 2010). Acceptable values of the outer loading, of observed variables, are 0.7 or a value greater than that. Outer loadings with a value below 0.7 should be discarded right away[68].

For this specific study, 0.7 was determined to be the cut-off value for the outer loading. As noted in Table 3, the values for the outer loadings lied in between 0.7022 and 0.898 . For the purpose of internal consistency evaluation in the construct reliability, Cronbach's Alpha and Composite Reliability (CR) were used. Upon comparison of the two, CR is believed to yield better results for internal consistency as the standardized loadings of the observed variables is kept (Chin \& Marcoulides 1998).

All the variables in Table 3 depict that, the Cronbach's Alpha is above 0.70, and this indicates that all the constructs in the table have higher reliability in terms of measurement. According to Fornell \& Larcker (Fornell \& Larcker 1981), they explained in their works that, construct validity measures the degree to which a measurement represents and rationally associates the detected phenomenon to the construct through the major theory, while according to (Ringle \& Becker 2015), assessment is done through convergent validity and discriminant validity. From Table 3, The Average Variance Extracted (AVEs) and the composite reliability (CR) has satisfied the minimum of 0.5 and 0.70 respectively (Fornell \& Larcker 1981),(Ringle \& Becker 2015). This shows that the convergent validity is clearly adequate.

Table 3 Construct Reliability and Validity

\begin{tabular}{|c|c|c|c|c|c|}
\hline Factor & Items & Loading & $\begin{array}{l}\text { Cronbach's } \\
\text { Alpha }\end{array}$ & $\begin{array}{l}\text { composite } \\
\text { reliability }\end{array}$ & $\begin{array}{l}\text { Average } \\
\text { Variance } \\
\text { Extracted }\end{array}$ \\
\hline \multirow{6}{*}{$\begin{array}{l}\text { Information } \\
\text { quality }\end{array}$} & iq1 & 0.846 & \multirow{6}{*}{0.922} & \multirow{6}{*}{0.939} & \multirow{6}{*}{0.720} \\
\hline & iq2 & 0.898 & & & \\
\hline & iq3 & 0.868 & & & \\
\hline & $\mathrm{iq} 4$ & 0.869 & & & \\
\hline & iq5 & 0.818 & & & \\
\hline & iq6 & 0.789 & & & \\
\hline \multirow[t]{6}{*}{$\begin{array}{l}\text { Service } \\
\text { quality }\end{array}$} & sq1 & 0.835 & \multirow{6}{*}{0.868} & \multirow{6}{*}{0.901} & \multirow{6}{*}{0.603} \\
\hline & $\mathrm{sq} 2$ & 0.842 & & & \\
\hline & sq3 & 0.765 & & & \\
\hline & sq4 & 0.702 & & & \\
\hline & sq5 & 0.752 & & & \\
\hline & sq6 & 0.753 & & & \\
\hline \multirow{6}{*}{$\begin{array}{l}\text { System } \\
\text { quality }\end{array}$} & syq1 & 0.827 & \multirow{6}{*}{0.908} & \multirow{6}{*}{0.929} & \multirow{6}{*}{0.687} \\
\hline & syq2 & 0.869 & & & \\
\hline & syq3 & 0.843 & & & \\
\hline & syq4 & 0.836 & & & \\
\hline & syq5 & 0.846 & & & \\
\hline & syq6 & 0.746 & & & \\
\hline \multirow{6}{*}{$\begin{array}{l}\text { User } \\
\text { satisfaction }\end{array}$} & us1 & 0.869 & \multirow{6}{*}{0.948} & \multirow{6}{*}{0.958} & \multirow{6}{*}{0.793} \\
\hline & us2 & 0.896 & & & \\
\hline & us3 & 0.899 & & & \\
\hline & us4 & 0.916 & & & \\
\hline & us5 & 0.867 & & & \\
\hline & us6 & 0.896 & & & \\
\hline
\end{tabular}

Moreover, the attempt taken afterward was the assessment of the latent constructs through discriminant validity. Discriminant validity elaborated that the definite variable in any construct is different from the rest of the constructs, including that the value for its cross-loading in the latent variable is higher than that in the rest of the constructs (Sarstedt et al. 2014). 
Table 4 Discriminant Validity

\begin{tabular}{|l|l|l|l|l|}
\hline & information quality & service quality & system quality & user satisfaction \\
\hline information quality & 0.849 & & & \\
\hline service quality & 0.699 & 0.776 & & \\
\hline system quality & 0.755 & 0.633 & 0.829 & \\
\hline user satisfaction & 0.787 & 0.693 & 0.783 & 0.891 \\
\hline
\end{tabular}

Table 4 above shows the discriminant analysis with regards to the scales used in this study. Discriminant analysis requires a factor to correlate higher than with any other construct on its scale (Messick 1994). All the scales in Table 4 shows the constructs loading higher than any other factor on their scales. Information quality on its scale had a value of about (0.84) which is higher than any other construct on that scale. Service quality and system quality had a value of (0.77) and (0.82) respectively. user satisfaction is $(0.89)$ which is higher than any other factors on their scales.

"The Fornell and Larcker model and cross-loadings were utilized to assess discriminant legitimacy [69]. The recommended standard is that a build ought not to demonstrate a similar variance as whatever other development that is more than its AVE esteem (Sarstedt et al. 2014).. Table 5 demonstrates the Fornell and Larcker paradigm trial of the model where the squared connections were contrasted and the relationships from other dormant develop. Table 5 demonstrates that the majority of the connections were small in comparison to the squared foundation of the normal difference applied along the diagonals, suggesting major discriminant legitimacy. This confirmed that the observed factors in each build demonstrated the given inert variable confirming the deviating accuracy of the model, though, Table 6 demonstrates that the cross-loading of every watched variable was more than the between inter-connections of the construct of the various watched factors in the model. In this manner, these discoveries affirmed the cross-loadings evaluation principles and gave satisfactory approval to the discriminant validity of the estimation model.

As this closes, the prescribed model was expected to be considerable, as to adequate unwavering reliability, discriminant validity, convergent validity and the evaluation of the research model.

Table 5 Fornell-Larcker Criterion

\begin{tabular}{|l|l|l|l|l|}
\hline & $\mathrm{Iq}$ & $\mathrm{Sq}$ & syq & Us \\
\hline information quality & 0.849 & & & \\
\hline service quality & 0.699 & 0.776 & & \\
\hline system quality & 0.755 & 0.633 & 0.829 & \\
\hline user satisfaction & 0.787 & 0.693 & 0.783 & 0.891 \\
\hline
\end{tabular}


Table 6 Cross Loading

\begin{tabular}{|l|l|l|l|l|}
\hline & information quality & service quality & system quality & user satisfaction \\
\hline iq1 & 0.846 & 0.619 & 0.732 & 0.704 \\
\hline iq2 & 0.898 & 0.617 & 0.696 & 0.710 \\
\hline iq3 & 0.868 & 0.592 & 0.604 & 0.657 \\
\hline iq4 & 0.869 & 0.625 & 0.671 & 0.715 \\
\hline iq5 & 0.818 & 0.565 & 0.547 & 0.581 \\
\hline iq6 & 0.789 & 0.537 & 0.574 & 0.622 \\
\hline sq1 & 0.639 & 0.835 & 0.581 & 0.618 \\
\hline sq2 & 0.542 & 0.842 & 0.448 & 0.562 \\
\hline sq3 & 0.504 & 0.765 & 0.385 & 0.469 \\
\hline sq4 & 0.368 & 0.702 & 0.419 & 0.403 \\
\hline sq5 & 0.492 & 0.752 & 0.514 & 0.463 \\
\hline sq6 & 0.640 & 0.753 & 0.562 & 0.643 \\
\hline syq1 & 0.617 & 0.548 & 0.827 & 0.666 \\
\hline syq2 & 0.604 & 0.494 & 0.869 & 0.648 \\
\hline syq3 & 0.602 & 0.541 & 0.843 & 0.642 \\
\hline syq4 & 0.670 & 0.575 & 0.836 & 0.687 \\
\hline syq5 & 0.621 & 0.467 & 0.846 & 0.634 \\
\hline syq6 & 0.641 & 0.520 & 0.746 & 0.611 \\
\hline us1 & 0.674 & 0.673 & 0.735 & 0.869 \\
\hline us2 & 0.702 & 0.571 & 0.721 & 0.896 \\
\hline us3 & 0.687 & 0.668 & 0.685 & 0.899 \\
\hline us4 & 0.732 & 0.637 & 0.722 & 0.916 \\
\hline us5 & 0.699 & 0.547 & 0.637 & 0.867 \\
\hline us6 & 0.709 & 0.603 & 0.679 & 0.896 \\
\hline & & & & \\
\hline
\end{tabular}

\subsection{Hypothesis Test}

Hypothesis 1 (H1). Information quality attribute has a substantial and affirmative influence on user satisfaction (students)

Hypothesis 2 (H2). Service quality attribute has a substantial and affirmative influence on user satisfaction (students)

Hypothesis 3 (H3). System quality attribute has a substantial and affirmative influence on user satisfaction (students)

Similarities were found in the path coefficients in the PLS and the standardized b-coefficient in the Regression analysis. The significance of the hypothesis was verified using the b-value. Estimated variation in the dependent construct for a unit variation in the independent construct(s) was denoted by the value of $b$.

For the hypothesized model, the b-value was calculated for every path. The larger the b-value, the bigger the considerable effect was noted on the endogenous latent construct. However, the significance level of the b-value had to be tested using the T-statistics test. Through the process, an evaluation was done to determine the importance of the hypothesis (Chin \& Marcoulides 1998). Now, to assess the significance of the path coefficient and the Tstatistics values, a bootstrapping procedure was carried out for the study using 1000 sub-samples with no significant changes. It is described in Table 7.

Table 7 the significance of the path coefficient and the T-statistics values

\begin{tabular}{|l|l|l|l|l|l|}
\hline \multicolumn{2}{|l|}{ Hypothesis path } & Standerize beta & T statics & P value & Action \\
\hline H1 & Iq --- Us & 0.351 & 8.025 & 0.000 & accepted \\
\hline H2 & Sq---Us & 0.200 & 4.892 & 0.000 & accepted \\
\hline H3 & Syq---Us & 0.391 & 10.354 & 0.000 & accepted \\
\hline
\end{tabular}

In $\mathrm{H} 1$, we anticipated that the information quality would suggestively and definitely effect user satisfaction. As expected, the results in Table 7 and Figure 1 assured that the information quality pointedly impacted user 
satisfaction $(b=0.351, T=8.025, \mathrm{p}<0.000)$. Therefore, $\mathrm{H} 1$ was strongly encouraged. Moreover, when perceiving the direct and affirmative effect of the service quality feature on quality of the project $(\mathrm{H} 2)$, the conclusions from Table 7 and Figure 1 recommended that the service quality feature certainly affected user satisfaction $(b=0.200$, $\mathrm{T}=4.892, \mathrm{p}<0.000$ ), and confirmed $\mathrm{H} 2$. The impact of the system quality feature on user satisfaction was affirmative and important $(\mathrm{b}=0.391, \mathrm{~T}=10.354, \mathrm{p}<0.000)$, presenting that $\mathrm{H} 3$ was sustained.

The higher the beta coefficient (b), the more compelling the result of an exogenous latent construct on the endogenous latent construct. Table 7 and Figure 1 displayed that the system quality feature had the highest path coefficient of $b=0.391$ when compared to other $b$ values in the model. Whereas, the service quality feature had a minimum influence on the quality of the project with $b=0.200$. Figure 2 displays the visual representation of all path coefficients of the model.

Figure 1 Structural modeling on quality of the system, quality of information, quality of service and user satisfaction

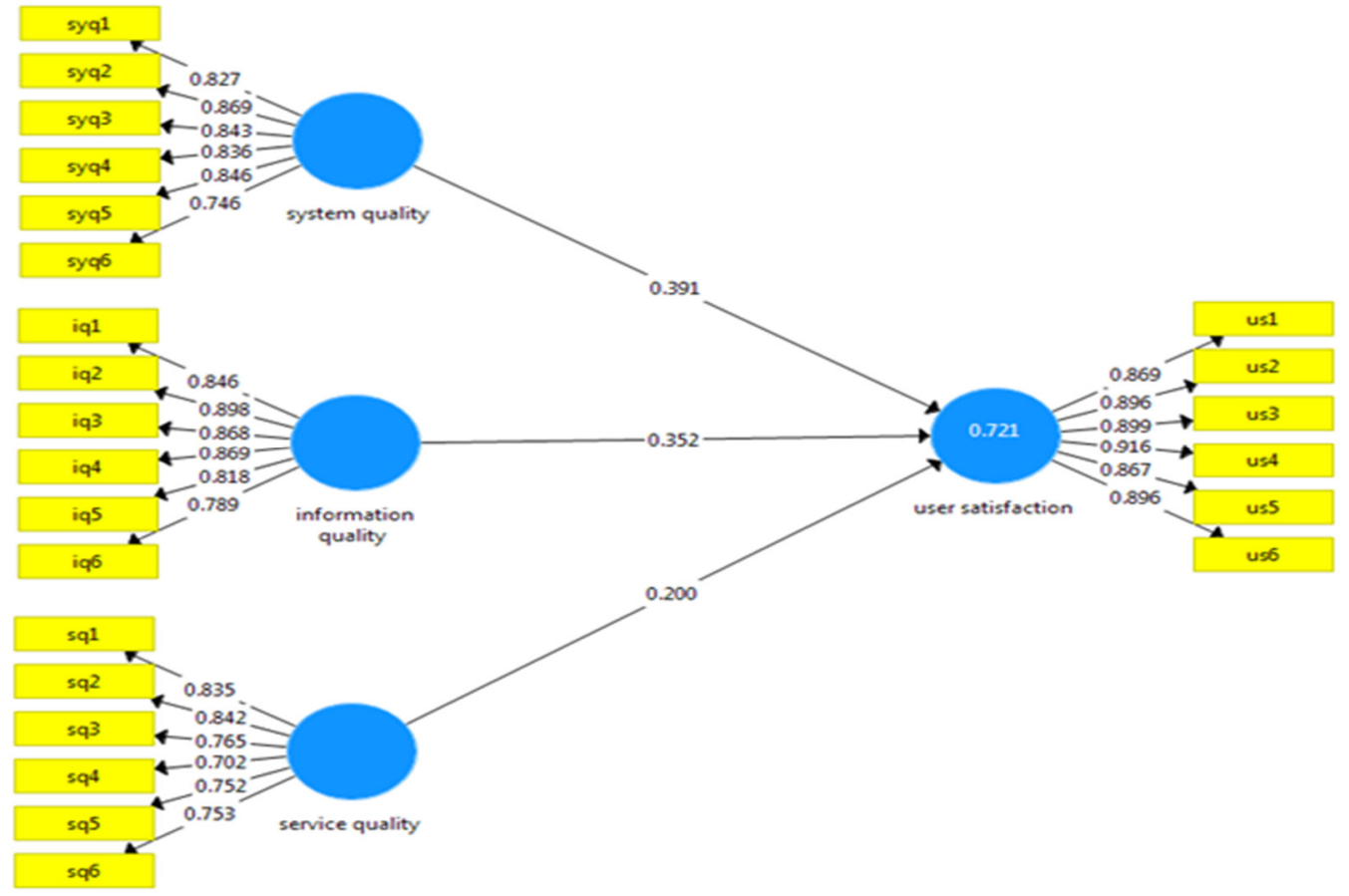

Figure 2. Graphical representation of the path coefficient.

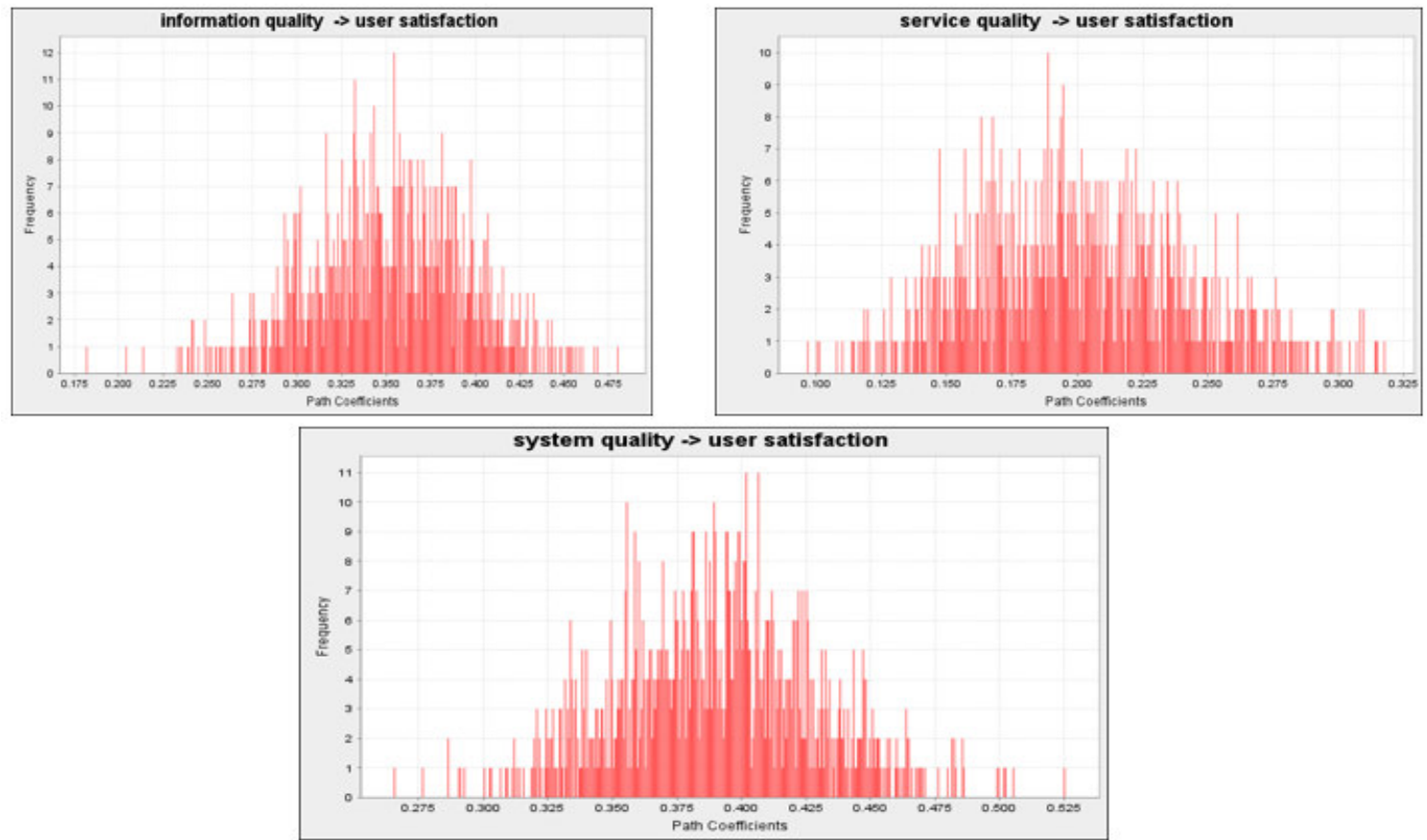




\subsection{Root Mean Square ( Standardized SRMR)}

SRMR is an index of the average of standardized obtained remainders between the observed and hypothesized covariance matrices (Fang 2007).

The obtained resulting value is the obtained measure of the fit estimate of the model. If the value of SRMR is $<=0.08$, following, the studied model has a good fit (Hu \& P.M 1998), however, a lower SRMR value is always a better-suited fit. Table number 8 displays that pertaining to the model discussed in the course of this study, the value of SRMR was 0.06, which consequentially proves that the fit of the study's model was good. Apart from this, the Chi-square and the NFI were also measured and yielded values equal to 2005.072 and 0.818 respectively.

Table 8 Fit Summary

\begin{tabular}{|l|l|}
\hline & Estimated Model \\
\hline SRMR & 0.067 \\
\hline d_ULS & 1.328 \\
\hline d_G1 & 0.952 \\
\hline d_G2 & 0.731 \\
\hline Chi-Square & $2,005.072$ \\
\hline NFI & 0.818 \\
\hline
\end{tabular}

\subsection{Correlation Coefficient of Latent Variables}

Table number 9 discusses the latent variable correlation coefficient. Table number 9 reveals that a major correlation exists between two constructs; latent exogenous and the latent endogenous.

Table 9 Latent Variable Correlations

\begin{tabular}{|l|l|l|l|l|}
\hline & information quality & service quality & system quality & user satisfaction \\
\hline information quality & 1.000 & 0.699 & 0.755 & 0.787 \\
\hline service quality & 0.699 & 1.000 & 0.633 & 0.693 \\
\hline system quality & 0.755 & 0.633 & 1.000 & 0.783 \\
\hline user satisfaction & 0.787 & 0.693 & 0.783 & 1.000 \\
\hline
\end{tabular}

A detailed analysis of the structural and measurement models was carried out and it was concluded that both the models were affirmed. The hypothesis which was made was statistically significant and thus, were all accepted.

The outcomes of this process assist a higher and precise concept of the attributes influencing user satisfaction and can aid in establishing a set of plans to leave the user contentment failures behind.

\section{Discussion}

The prime goal of the study is to analyze the factor that influenced user satisfaction through the PLS-SEM technique and a detailed analysis of basic factors impacting the user contentment as observed by the Jiangsu University's overseas students.

Moreover, this study regarded the web portal functional information system and how the students comprehend its applications in completing their requirements on the system. The final conclusion exhibits the sustaining importance of the information on user satisfaction. The argument is based on the consequences of these interactions. The study states that the importance of information quality on the user satisfaction of the overseas education college web portal, with regards to completeness, accuracy, understandability, timeliness, and relevance of the data it contains. These factors underlie the insight of users and form criteria for analyzing the system's efficiency. The associations between information quality and user satisfaction are highly encouraged in the literature (Iivari 2005),( Wu \& Wang 2006). Studies (Rai et al. 2002),( Chiu et al. 2010) show a consistent association between the quality of the information and user satisfaction at the separate unit of analysis. Studies particularly assessing the information quality factors of websites, such as layout and content have shown important relationships among user satisfaction and these constructs. Study (Kim et al. 2002) exhibits that sustaining information quality eventually leads to user satisfaction. This result is important as it concludes that the satisfaction with the information system is directly proportional to the satisfaction of the student. The last SEM results show that the information quality attribute had the largest coefficient in terms of path i.e. $b=0.391$ with the comprehensive influencing user satisfaction.

Assessing the quality of the service more widely, rather than just with the regards to active personnel and how they are trained, there is still controversial backing for its impact on user opinion. Applying the SERVQUAL tool, which assesses assumptions and insights that users have on the quality of the service (Lee et al. 1994), likewise, found that quality of service is emphatically and significantly associated to user opinion of information facilities in an interview of students grading the Computer Services department of the university. The study 
observed the significance of service quality on user satisfaction of the overseas education college school web portal, measured when quantifying competence, speed, dependability, Responsiveness, and security, however Among the the three user satisfaction impacting factors, a service quality factor of $(b=0.200)$ was observed to cast minimal impact on user satisfaction

In two separate studies, (Palmer 2002) carried out on websites, quality of the system, considered as download time and reliability, was notably associated with user satisfaction. Moreover,( Devaraj \& Kohli 2002) analyzed comprehend ease of use to be remarkably connected to user satisfaction. Therefore, firm support is there for the association between the level of user satisfaction and quality of the system (Iivari 2005).this study confirms the University of the system quality attribute in predicting IS performance in term of reliability, download time, ease of use, global standardization and accessibility, The system quality was concluded as the $2^{\text {nd }}$ biggest influencing factor $(b=0.351)$ within factors affecting user satisfaction .

\section{Conclusion}

The study was a descriptive survey of overseas students of Jiangsu University The prime goal of the study is to analyze the factor that influenced user satisfaction through the PLS-SEM technique and a detailed analysis of basic factors impacting the user satisfaction as observed by the Jiangsu University's overseas students.

Moreover, this study regarded the web portal functional information system and how the students comprehend its applications in satisfying their requirements on the system. The final conclusion exhibits the sustaining importance of the information on user satisfaction. The argument is based on the consequences of these interactions. The study states that the importance of information quality on the user satisfaction of the overseas education college web portal, with regards to completeness, accuracy, understandability, timeliness, and relevance of the data it contains. These factors underlie the insight of users and form criteria for analyzing the system's efficiency. This study exhibits that sustaining information quality eventually leads to user satisfaction. This result is important as it concludes that the satisfaction with the information system is directly proportional to the satisfaction of the student. The last SEM results show that the system quality attribute had the largest coefficient in terms of path i.e. $b=0.391$ with the comprehensive influencing user satisfaction. The study observed the significance of service quality on user satisfaction of the overseas education college school web portal, measured when quantifying competence, speed, dependability, Responsiveness and security .this study confirms the University of the INFORMATION quality attribute in predicting IS performance in term of reliability, download time, ease of use, global standardization and accessibility.

\section{References}

H. Gao and H. de Wit, (2017), "China and international student mobility," International Higher Education, pp. 35.

X. Liu, L. Zhou, and G. Chen, (2019) "Research on the Construction Path of High-Level Universities Under the Background of'Double World-Class' in China: Taking Jiangsu Province as an Example".

B. P. Creemers,(2002),"From school effectiveness and school improvement to effective school improvement: Background, theoretical analysis, and outline of the empirical study," Educational Research and Evaluation, vol. 8, pp. 343-362.

P.-N. Tan, V. Kumar, and J. Srivastava, (2004),"Selecting the right objective measure for association analysis," Information Systems, vol. 29, pp. 293-313.

G.-E. Song, K. Kim, D.-J. Lee, and N.-S. Joo, (2011),"Whole body vibration effects on body composition in the postmenopausal korean obese women: pilot study," Korean journal of family medicine, vol. 32, p. 399.

Y. Vardi and E. Weitz,(2002), "Using the theory of reasoned action to predict organizational misbehavior," Psychological reports, vol. 91, pp. 1027-1040.

S. Petter and E. R. McLean,(2009), "A meta-analytic assessment of the DeLone and McLean IS success model: An examination of IS success at the individual level," Information \& Management, vol. 46, pp. 159-166.

K. Desai and S. Mahalakshmi,(2018), "Impressions of service quality dimensions on customers intention to use IoT at Bangalore Electricity Supply Company (BESCOM)," Journal of advance management Research, vol. 6, pp. 74-8.

B. Thompson and J. Nier,(2005), "A Marriage of Opposites? Integrating Exploratory and Confirmatory Factor Analysis," Psyccritiques, vol. 50.

A. Tatnall, (2005),"Portals, Portals Everywhere," Web Portals the New Gateways to Internet Information \& Services.

A. Tatnall,(2009) "Gateways to portals research," International Journal of Web Portals (IJWP), vol. 1, pp. 1-15.

R. K. Rainer Jr and A. W. Harrison, (1993),"Toward development of the end user computing construct in a university setting," Decision Sciences, vol. 24, pp. 1187-1202.

M. Igbaria and S. A. Nachman, (1990), "Correlates of user satisfaction with end user computing: an exploratory study," Information \& Management, vol. 19, pp. 73-82. 
W. H. DeLone and E. R. McLean,(1992) "Information systems success: The quest for the dependent variable," Information systems research, vol. 3, pp. 60-95.

M. Igbaria and M. Tan,(1997) "The consequences of information technology acceptance on subsequent individual performance," Information \& management, vol. 32, pp. 113-121.

J. L. Whitten and L. D. Bentley,(2007) "System analysis and design for the global enterprise," ed: New York: McGraw-Hill/Irwin.

H. Tolley and B. Shulruf,(2009), "From data to knowledge: The interaction between data management systems in educational institutions and the delivery of quality education," Computers \& Education, vol. 53, pp. 11991206.

J.-P. Van Belle, J. Nash, and M. Eccles, (2010), "Discovering Information Systems: an exploratory approach: University of Cape Town".

T. Saarinen,(1996), "An expanded instrument for evaluating information system success," Information \& management, vol. 31, pp. 103-118.

R. L. Nolan and H. Seward, (1974)"Measuring user satisfaction to evaluate information systems," Managing the data resource function, pp. 253-275.

R. L. Nolan,(1974) "Managing the Data Resource Function, West Pub," Co.: Dallas.

P. Ein-Dor, E. Segev, D. Blumenthal, and I. Millet, (1984),"Perceived importance, investment and success of MIS, or the MIS zoo," SYST. OBJECT. SOLUTIONS., vol. 4, pp. 61-67.

S. R. Snitkin and W. R. King, (1986), "Determinants of the effectiveness of personal decision support systems," Information \& Management, vol. 10, pp. 83-89.

J. E. Bailey and S. W. Pearson, (1983), "Development of a tool for measuring and analyzing computer user satisfaction," Management science, vol. 29, pp. 530-545.

B. Ives, M. Olson, and J. J. Baroudi, (1983),"The measurement of user information satisfaction,".

J. J. Baroudi and W. J. Orlikowski,( 1988), "A short-form measure of user information satisfaction: a psychometric evaluation and notes on use," Journal of Management Information Systems, vol. 4, pp. 44-59.

D. L. Amoroso and P. H. Cheney, (1991), "Testing a causal model of end-user application effectiveness," Journal of Management Information Systems, vol. 8, pp. 63-89.

W. H. DeLone and E. R. McLean, (2002), "Information systems success revisited," in Proceedings of the 35th Annual Hawaii International Conference on System Sciences, pp. 2966-2976.

E. J. Garrity and G. L. Sanders, "Introduction to information systems success measurement," in Information systems success measurement, 1998, pp. 1-12.

E. B. Swanson, (1974),"Management information systems: appreciation and involvement," Management science, vol. 21, pp. 178-188.

k. kim, "User satisfaction: a synthesis of three different perspectives," journal information system, 1989.

W. J. Doll, and G. Torkzadeh,(1989),"A Discrepancy Model of End-User Computing Involvement," Management Science 35.10

M.-Y. K. Peter S , (1996), "A Partial Test and Development of Delone and Mclean's Model of IS Success," Australasian Journal of Information Systems .

F. Qawasmeh, A. Tahir, H. Tresnjo, A. Zilic, and J. Ibrahim, (2014)"The student portal performance- comparative study (GSM-IIUM)".

I. A. M Fishbein, (1977),"Belief, Attitude, Intention and Behavior: An Introduction to Theory and Research," philarchive.org.

P. Seddon and M. Y. Kiew, (1996), "A Partial Test and Development of Delone and Mclean's Model of IS Success," Ajis Australasian Journal of Information Systems, vol. 4, pp. 137-148.

F. D. Davis,( 1989), "Perceived Usefulness, Perceived Ease of Use, and User Acceptance of Information Technology," Mis Quarterly, vol. 13, pp. 319-340.

W. H. Delone and E. R. McLean,( 2003), "The DeLone and McLean model of information systems success: a tenyear update," Journal of management information systems, vol. 19, pp. 9-30.

L. F. Pitt, R. T. Watson, and C. B. Kavan,( 1995), "Service Quality: A Measure of Information Systems Effectiveness," Mis Quarterly, vol. 19, pp. 173-187.

P. B. Seddon, (1997)," A Respecification and Extension of the DeLone and McLean Model of IS Success," Information Systems Research.

J. J. Jiang, G. Klein, and C. L. Carr, (2002),"Measuring information systems service quality: SERVQUAL from the other side".

M. Jennex and L. Olfman,(2002),"Organizational Memory/Knowledge Effects on Productivity: A Longitudinal Study," in Hawaii International Conference on System Sciences.

U. R. Kulkarni, S. Ravindran, and R. Freeze, (2006), "A Knowledge Management Success Model: Theoretical Development and Empirical Validation," Journal of Management Information Systems, vol. 23, pp. 309-347.

A. Molla, and Paul S. Licker, (2001), " E-commerce systems success: an attempt to extend and respecify the 
DeLone and McLean model of IS success," J. Electron. Commerce Res.

K. Zhu, and Kenneth L. Kraemer, (2005),"Post-adoption variations in usage and value of e-business by organizations: cross-country evidence from the retail industry," Information systems research.

I. Munro, J. Ballantine, M. Bonner, M. Levy, and P. L. Powell, (1996) "The 3-D Model of Information Systems Success: The Search for the Dependent Variable Continues," Information Resources Management Journal, vol. 9, pp. 5-15.

B. L. Myers, L. A. Kappelman, and V. R. Prybutok,( 1997), "A comprehensive model for assessing the quality and productivity of the information systems function: toward a theory for information systems assessment," in Information Systems Success Measurement.

R. L. Nolan, (1973), "Managing the computer resource: a stage hypothesis".

P. B. Seddon, R. Patnayakuni, M. Bowtell, and E. Young,( 1999), "Dimensions of information systems success," Communications of the Ais, vol. 2, pp. 2966 - 2976.

S. Petter, W. Delone, and E. Mclean, (2008), "Measuring information systems success: models, dimensions, measures, and interrelationships," European Journal of Information Systems, vol. 17, pp. 236-263.

J. Iivari,( 2005)," An empirical test of the DeLone-McLean model of information system success".

T. W. P. A, (2005), "A Theoretical Integration of User Satisfaction and Technology Acceptance," [J]. Information Systems Research.

J. H. Wu and Y. M. Wang,(2006), Measuring KMS success: A respecification of the DeLone and McLean's model,

A. Leclercq, (2007) "The Perceptual Evaluation of information Systems Using the Construct of User Satisfaction: Case Study of a Large French Group".

K. Özdamar, (2017),"Ölçek ve test geliştirme yapısal eşitlik modellemesi IBM SPSS, IBM SPSS AMOS ve MINTAB uygulamal1,".

J. F. Hair, B. Black, B. Babin, R. E. Anderson, and R. L. Tatham, Multivariate Data Analysis, 6/E, 1987.

C. W. Ringle, S.; Becker, J. (2015) "SmartPLS 3".

J. A. Bamgbade, A. M. Kamaruddeen, M. N. M. Nawi, R. Z. Yusoff, and R. A. Bin, (2017),"Does government support matter? Influence of organizational culture on sustainable construction among Malaysian contractors," International Journal of Construction Management, pp. 1-15,

C.-L. J. Lin, (2017),"Exploring Interface Problems in Taiwan's Construction Projects Using Structural Equation Modeling," Sustainability.

D. Gefen,( 2000),"Structural Equation Modeling and Regression: Guidelines for Research Practice Structural,".

J. R. Henseler, C.M.; Sinkovics, R, (2009), "The Use of Partial Least Squares Path Modeling in International Marketing.," Social Science Electronic Publishing,.

J. F. Hair, C. M. Ringle, and M. Sarstedt,( 2014), "Partial Least Squares Structural Equation Modeling: Rigorous Applications, Better Results and Higher Acceptance $\lesssim$, , Long Range Planning, vol. 47, pp. 392-392.

D. X. Peng and F. Lai,( 2012), "Using partial least squares in operations management research: A practical guideline and summary of past research $\succsim$," Journal of Operations Management, vol. 30, pp. 467-480.

R. Ho,( 2006), " Handbook of Univariate and Multivariate Data Analysis and Interpretation with SPSS".

J. F. Hair, M. Sarstedt, C. M. Ringle, and J. A. Mena, (2012),"An assessment of the use of partial least squares structural equation modeling in marketing research," Journal of the Academy of Marketing Science, vol. 40, pp. 414-433.

R. C. M. Hair J F , Sarstedt M , (2011), "PLS-SEM: Indeed a Silver Bullet," Journal of Marketing Theory \& Practice,

O. Götz, K. Liehr-Gobbers, and M. Krafft, (2010), "Evaluation of Structural Equation Models Using the Partial Least Squares (PLS) Approach".

W. W. Chin and G. Marcoulides, "The partial least squares approach to structural equation modeling," 1998.

C. Fornell and D. F. Larcker,( 1981), "Evaluating Structural Equation Models with Unobservable Variables and Measurement Error," Journal of Marketing Research, vol. 18, pp. 39-50.

M. R. Sarstedt, Christian M. \& Smith, Donna \& Reams, Russell \& Hair, Joseph F.,( 2014), "Partial least squares structural equation modeling (PLS-SEM): A useful tool for family business researchers" Journal of Family Business Strategy, Elsevier, vol. vol. 5(1), pp. pages 105-115.

S. Messick,( 1994), "VALIDITY OF PSYCHOLOGICAL ASSESSMENT: VALIDATION OF INFERENCES FROM PERSONS' RESPONSES AND PERFORMANCES AS SCIENTIFIC INQUIRY INTO SCORE MEANING," Ets Research Report, vol. 1994, pp. i-28.

F. C. Fang, (2007),"Sensitivity of Goodness of Fit Indexes to Lack of Measurement Invariance," Structural Equation Modeling A Multidisciplinary Journal, vol. 14, pp. 464-504.

L. B. Hu, P.M. , (1998), "Fit Indices in Covariance Structure Modeling: Sensitivity to Underparameterized ModelMisspecification," Psychol. Methods, pp. 424-453.

A. Rai, S. S. Lang, and R. B. Welker, (2002),"Assessing the Validity of IS Success Models: An Empirical Test and Theoretical Analysis," Information Systems Research, vol. 13, pp. 50-69. 
C. M. Chiu, C. S. Chiu, and H. C. Chang, (2010), "Examining the integrated influence of fairness and quality on learners' satisfaction and Web-based learning continuance intention," Information Systems Journal, vol. 17, pp. 271-287.

J. L. J. Kim, K. Han and M. Lee,( 2002), "Business as buildings: metrics for the architectural quality of internet businesses," Information Systems Research, vol. vol. 13(3), pp. pp. 239-254.

W. J. K. a. C. C. Lee, (1994), "Perceived service quality and user satisfaction with the information services function," Decision Sciences, vol. vol. 25(5), pp. pp. 737-766.

J. Palmer, (2002),"Web site usability, design and performance metrics," Information Systems Research, vol. vol. 13(1), pp. pp. 151-167.

M. F. S. Devaraj, and R. Kohli,( 2002), "Antecedents of B2C channel satisfaction and preference: validating ecommerce metrics," Information Systems Research, vol. vol. 13(3), pp. pp.316-333. 